\title{
DEMOCRACIA, CONFLITO E CONTROLE SOCIAL: O FENÔMENO TOTALITÁRIO É POSSIVEL DENTRO DA SOCIEDADE DE IGUAIS?
}

\author{
Fabiana Marion Spengler ${ }^{1}$ \\ Giancarlo Montagner Copelli²
}

\begin{abstract}
Resumo
Observando o conflito como um importante elemento tanto na formação dos vínculos sociais, quanto no movimento da sociedade, este estudo busca analisar, a partir de uma abordagem multidisciplinar, as tensões contidas na relação entre grupo e indivíduo. Estas tensões vêm no presente texto exemplificadas por aquelas resultantes de relações que ameaçam tanto a unidade do tecido social quanto a liberdade do próprio indivíduo. Ou seja, este estudo enfrenta como problema a questão, aparentemente paradoxal, que lhe dá título: o fenômeno totalitário é possível dentro de uma democracia? Para tal, este texto está dividido em três partes. Na primeira, busca-se, à luz do pensamento freudiano, recuperar a discussão teológica em torno da autonomia humana, no momento em que o poder da Igreja aproximava-se do poder político. Ainda na primeira parte, observa-se a Revolução Francesa como o momento de inversão deste pensamento, dominante durante todo o Medievo. Já na segunda parte, observa-se o totalitarismo como a completa supressão da autonomia humana, abafando os conflitos e freando o movimento da própria sociedade. Por fim, na terceira parte, são observadas as restrições típicas do totalitarismo na democracia. Para esta pesquisa foi utilizado o método hipotético-dedutivo. Já a técnica utilizada foi a de pesquisa bibliográfica.
\end{abstract}

Palavras-chave: Democracia; Totalitarismo; Conflito; Controle Social; Estado.

\section{INTRODUÇÃO}

Considerando o mito freudiano descrito em Totem e Tabu (2013), o surgimento da civilização é o produto do conflito contido na relação entre o pai-tirano, senhor absoluto de todas as coisas, e os irmãos,

\footnotetext{
${ }^{1}$ Mestre em Direito (Área de Concentração em Direitos Humanos) pela Universidade Regional do Noroeste do Estado do Rio Grande do Sul, especialista em Ética e Filosofia Política pela AVM Faculdades Integradas. E-mail: giancarlocopelli@yahoo.com.br 2 Pós-doutora em Direito pela Università degli Studi di Roma Tre, em Roma, na Itália, com bolsa CNPq (PDE). Docente dos cursos de Graduação e Pós Graduação lato e stricto sensu da UNISC e da UNIJUI, Coordenadora do Grupo de Pesquisa "Políticas Públicas no Tratamento dos Conflitos" vinculado ao CNPq, coordenadora do Projeto de Pesquisa "Entre a jurisdição e a mediação: o papel político/sociológico do terceiro no tratamento dos conflitos" coordenado pela autora e financiado pelo CNPq, chamada 43/2013 - Ciências Humanas, Sociais e Sociais Aplicadas, no do processo 408582/2013; pesquisadora do projeto "Multidoor courthouse system - avaliação e implementação do sistema de múltiplas portas (multiportas) como instrumento para uma prestação jurisdicional de qualidade, célere e eficaz” financiado pelo CNJ e pela CAPES; coordenadora e mediadora judicial do projeto de extensão: "A crise da jurisdição e a cultura da paz: a mediação como meio democrático, autônomo e consensuado de tratar conflitos” financiado pela Universidade de Santa Cruz do Sul - UNISC.E-mail: fabiana@unisc.br
} 
oprimidos pela onipotência paterna. Ainda de acordo com o mito, os irmãos, ao se reconhecerem na igual condição de submissão e impotência diante do poder paterno, tramam, em conluio, a morte do pai-tirano. $\mathrm{O}$ assassinato da figura opressora, considerado aqui como o momento seminal do social, é a gênese da sociedade: os componentes do grupo - os irmãos -, diante da mesma condição de impotência, submissão e opressão, se reconhecem como iguais, com necessidades e objetivos semelhantes ${ }^{3}$.

Entretanto, a morte do pai-tirano desencadeia um ciclo em torno da conquista e da manutenção do poder. Afinal, o assassinato tramado pelos irmãos põe abaixo a figura do poder, mas não elimina o lugar do poder, assumido pelos próprios assassinos. Daí decorre a necessidade de um pacto, voltado à proibição do assassinato, do conflito em si. É a partir do pacto, portanto, que se permite a manutenção do poder, agora compartilhado pelos irmãos. Manter o poder implica, assim, em controle sobre os demais, já que o mesmo conflito que funda o social é - de igual modo - a possibilidade de ação que o põe em risco. A partir da metáfora freudiana, portanto, é possível assentar - como premissa que sustenta esta discussão - as sociedades organizadas como, em linhas muito sucintas, dependentes do controle estatal que abafa ou trata os conflitos de seus indivíduos, como condição necessária para a sua própria manutenção.

Contemporaneamente, sobretudo após a Segunda Grande Guerra, a tensão contida entre poder e autonomia ganhou contornos muito significativos diante do fenômeno do totalitarismo, em tese a antítese dos regimes políticos surgidos a partir das ideias conflitantes ${ }^{4}$ contidas nas Luzes, e cujos marcos maiores foram, conforme Lefort (1991), as próprias revoluções ditas liberais, como a Americana, em 1776, e a Francesa, em 1789. Essa espécie de involução temporal, capaz de retroagir no tempo e assentar - como bem demonstra a própria História - regimes políticos diametralmente opostos àqueles edificados à luz dos Direitos do Homem, no século XVIII, em pleno século XX, contudo, parece ter ruído junto ao Muro de Berlin (TODOROV, 2012)5.

Isso não significa, entretanto, menor peso nas discussões acerca do totalitarismo na atualidade. Afinal, como bem pontuam Bobbio (2000) e Bielefeldt (2000), se os Direitos Humanos são produtos, como a própria democracia, históricos, ou seja, se estão alinhados às necessidades, mas, sobretudo, às condições da própria humanidade em um dado tempo - e somente a partir desses predicativos avançam -, o caminho contrário

\footnotetext{
${ }^{3}$ Sobre o assunto é interessante a leitura de RESTA, Eligio. Il diritto Fraterno. Roma-Bari: Laterza, 2005.

${ }^{4}$ Embora o Iluminismo seja formado por um conjunto de ideais que se aproximam, não podemos perder de vista, também, que uma das principais características desse período foi justamente a pluralidade de ideias, nem sempre alinhadas. Como exemplo, o Rousseau do Discurso sobre a origem e os fundamentos da desigualdade entre os homens (2009) discordava das ideias de Voltaire, outro iluminista, com suas Cartas Filosóficas (2007). Ambos eram iluministas.

${ }^{5}$ Embora alguns autores sejam enfáticos, caso de Todorov (2012), observar essas e outras ameaças externas à democracia como exclusivamente parte do passado merece ressalvas. Embora o mundo caminhe para uma ordem global - dentro da soberania dos Estados - democrática (PINKER, 2013), é importante não perder de vista países como a China, por exemplo - de economia aberta, mas ainda palco para um regime de forte controle estatal -, além de outros países, como a Coreia do Norte ou, ainda, o exemplo da Venezuela, na América do Sul.
} 
também é possível, de modo que novos condicionantes temporais podem, sim, ameaçar as democracias de modo geral, como demonstra o próprio exemplo do pós-guerra.

Entretanto, se essas discussões não podem - e talvez jamais poderão - ser esvaziadas por completo, ganha relevo, à luz deste século, outra abordagem - também em torno das tensões contidas entre a autonomia humana e as possibilidades de alteridade do grupo frente ao controle estatal e sua posição diante do conflito. É a que observa o controle do Estado, mesmo nas democracias, abafando os conflitos sem tratá-los, desequilibrando a competição política, cerceando a autonomia e, consequentemente, limitando a saudável condição de alteridade social, tornando, assim, estático o tecido social (MORAIS E SPENGLER, 2012). É a esta análise, portanto, que este texto se propõe.

É importante esclarecer que o presente texto se refere a um debate interdisciplinar, dialogando junto a diversas áreas do conhecimento, notadamente o Direito, a Política, a História, a Psicologia e a Sociologia, sem uma relação mais delimitada com a Filosofia do Direito. Exatamente por isso, deixou-se de examinar, de maneira mais específica, referenciais bibliográficos associados a essa área do conhecimento, como, entre outros, Michel Troper (Cos'è la filosofia del diritto, 2003), Ernildo Stein (Pensar é pensar a diferença: filosofia e conhecimento empírico, 2002, e Exercícios de fenomenologia, 2004), Sergio Cotta (Perchè il diritto, 1993), Michel Villey (Filosofia do direito: definições e fins do direito; os meios do direito, 2003) ou Castanheira Neves (O direito hoje e com que sentido, 2002), por exemplo, mais voltados a questões relacionadas a teorias da justiça ou às principais correntes do pensamento jurídico ao longo do tempo.

Nesse sentido, referenciais teóricos de base, que facultam a interdisciplinaridade aqui proposta, como Hannah Arendt - referência obrigatória ao estudo do totalitarismo, por exemplo, com Origens do totalitarismo: antissemitismo, imperialismo, totalitarismo (2012); Eugène Enriquez - fundamental para transitar da psicanálise ao social, com Da horda ao Estado: psicanálise do vínculo social (1990); Sigmund Freud - necessário para situar a discussão acerca do mito contido em Totem e Tabu (2013); bem como Claude Lefort - referência importante para a discussão democrática contemporânea, com Pensando o político: ensaios sobre democracia, revolução e liberdade (1991), entre outros, ganham prevalência. Demais autores renomados, que trabalham com conceituações correlatas ao presente estudo, tais como, por exemplo, Ernesto Laclau e Chantal Mouffe, com Hegemonía y estrategia socialista; hacia una radicalización de la democracia (1987), ao propor importante debate acerca do conceito de hegemonia, serão utilizados com parcimônia devido aos limites de tempo e de espaço impostos ao presente artigo e, principalmente, devido ao fato de que seus textos e teorias gerariam, por si só, novos e polêmicos escritos, merecendo que se sejam produzidos em espaço e momentos adequados.

Desse modo, este estudo está dividido em três partes distintas. A primeira, ao buscar a delimitação conceitual do papel do conflito para as sociedades democráticas - à luz do pensamento freudiano - recupera a 
discussão teológica que dominou a cristandade no fim da Antiguidade - já em direção ao Medievo - entre Pelágio e Agostinho - acerca da autonomia humana. O embate de ideias, observado, sobretudo, através das lentes de Todorov (2012), mostra-se importante a esta análise, à medida que o produto desta discussão assenta o poder da Igreja, justificando o controle e a limitação da autonomia humana, justamente no momento em que esta passa a preencher o espaço político deixado em aberto pelo Império Romano. Ou seja, embora o debate entre Pelágio e Agostinho revele um conteúdo eminentemente teológico, seu saldo ultrapassa as barreiras do sagrado, atingindo, também, o político.

Esse retorno é particularmente importante porque se, como bem ensina Dacanal (2013), o Ocidente é moldado a partir da política romana, do pensamento helênico e da simbiose religiosa formada pelo Judaísmo e pelo Cristianismo, consequentemente não apenas a discussão entre os pensadores antigos e seu produto, mas toda a linearidade que deles se segue, abarca o conjunto de heranças que, ao longo do tempo, deram forma à tensão entre poder e autonomia no Ocidente. Ou seja, todas as transformações pelas quais passou o Ocidente são, ao menos em tese, ligadas a essas heranças, recebendo, em algum momento ou circunstância, uma dada influência.

Ainda na primeira parte deste texto, observa-se a Revolução Francesa não apenas como um marco de ruptura com o modelo anterior, pondo abaixo o Antigo Regime ${ }^{6}$ ancorado ainda no debate que colabora decisivamente para assentar o poder da Igreja. A Revolução Francesa também é observada, acima disso, como um importante ponto de reflexão para os efeitos da inversão da forma política que propunha a limitação da autonomia e a completa submissão a um poder constituído, para um regime edificado sob as cores, sobretudo, da liberdade e da igualdade.

De posse desses argumentos, a segunda parte deste estudo volta-se para a análise das possibilidades totalitárias, enquanto propostas de controle absoluto e restrição completa da autonomia dos indivíduos, e, portanto, também da ausência da alteridade necessária ao movimento do tecido social, à luz destas formas políticas no século XX. Esta abordagem justifica-se, ao concluir tais experiências totalitárias, preliminarmente, como uma espécie de espelho ideal do controle absoluto, do consenso forçado à margem da competição, permitindo, portanto, observar como a supressão total da autonomia humana - incompatível com o conceito de indivíduo - leva as sociedades a um completo estado de apatia, freando o avanço - sobretudo dos direitos - ao limitar não apenas novas necessidades, mas, também, novos condicionantes para tal.

Por fim, sobretudo a partir da análise de Lefort (1991) e de Todorov (2012), observa-se como essas possibilidades restritivas, aparentemente tão típicas dos regimes totalitários em estado puro, podem, na contemporaneidade, ameaçar as democracias internamente, regulando os conflitos de forma a abafá-los, suprimindo autonomia e, consequentemente limitando a capacidade de alteridade, tão necessária ao movimento

\footnotetext{
${ }^{6}$ Antigo Regime ou Estado dos Reis que, a partir de meados do século XV, dá novos contornos políticos à Europa (BEDIN, 2008). vol. 08, nº. 04, Número Especial. Rio de Janeiro, 2015.pp. 2493-2516 
do tecido social, e, paradoxalmente, também determinante para o surgimento do poder hegemônico, conforme ensina Mendonça (2007), ao debruçar-se sobre a obra de Laclau. Enfim busca-se resposta à questão que dá título a esse estudo: $\mathrm{O}$ fenômeno totalitário é possível dentro da sociedade de iguais? Para esta pesquisa foi utilizado o método hipotético-dedutivo. Já a técnica utilizada foi a de pesquisa bibliográfica.

\section{ENTRE TOTENS E TABUS: A SUPRESSÃO DA AUTONOMIA HUMANA NA FORMAÇÃO DO OCIDENTE}

Buscando identificar e analisar o que considera inimigos íntimos da democracia ${ }^{7}$, Todorov (2012) propõe, inicialmente, uma discussão aparentemente desconexa com o modelo político inspirado nos ideais liberais do século XVIII: a controvérsia entre os postulados agostinianos e pelagianos, no século IV, quando o imperador romano Constantino - convertido ao Cristianismo - e seu sucessor, Teodósio, fizeram deste a religião oficial do Império, proibindo os ritos considerados pagãos ${ }^{8}$.

Conforme este autor, Pelágio, nascido por volta do ano 350 e um dos polos do debate que envolve a cristandade no momento em que a Igreja de Roma aproxima-se do poder político, pondera que "o ser humano não pode ser dotado de uma natureza inteiramente má. [...] O homem não é, ou não é somente, o lobo do homem”, ancorando sua premissa na própria interpretação do texto bíblico, conforme adverte Todorov (2012, p. 23): "Deus criou o homem, e Deus é bom". Logo, se o homem é criado à imagem e à semelhança de Deus, tende, portanto, à bondade, e não pode ser apenas mau. Entretanto, a questão vai além da análise teológica: a sequência lógica do pensamento pelagiano, sobretudo a partir da criação do homem à imagem e à semelhança de Deus, conduz o homem a uma condição de autonomia que ultrapassa os limites do religioso. Afinal...

O Deus do monoteísmo desfrutou de uma liberdade de vontade que the permitiu criar, a partir do nada, o mundo e o homem. Ora, se ele fabricou este último à sua imagem, portanto o homem, por sua vez, dispõe de uma vontade livre. [...] E, assim, como a vontade divina não conhece limites, a vontade humana pode ultrapassar todos os obstáculos (TODOROV, 2012, p. 24 - grifo nosso).

Dito de outro modo, se Deus criou o homem à sua imagem e semelhança - e Deus é um ente autônomo no Cristianismo -, o homem, por sua vez, também o é para Pelágio. Assim, as escolhas humanas - a autonomia para decidir entre o bem e o mal - são o produto de sua própria vontade, antecipando, de certa maneira, o imperativo categórico kantiano?.

\footnotetext{
7 Todorov (2012) parte da premissa de que as ameaças comumente associadas à democracia, como o totalitarismo e o comunismo, por exemplo, são externas ao regime democrático, e que outras possibilidades, mais atuais que as formas totalitárias, observadas, sobretudo, no século XX, são internas. Por isso, íntimas ao modelo. Entre essas ameaças, o autor destaca, entre outras, o messianismo, fenômeno que reúne muitas semelhanças com o totalitarismo, embora apresente, também, diferenças significativas. ${ }^{8}$ Importante não perder de vista que, segundo Bedin (2008), o período assinalado por Todorov (2012) corresponde à aurora do Medievo, com o declínio do Império Romano e a ascensão do poder papal, dando novos contornos políticos ao Ocidente.

9 Segundo PACHECO e NESI (2007, p. 201 - grifo nosso), o imperativo categórico kantiano determina a ação moral como aquela capaz de ser considerada como um modelo de moralidade, de modo que as ações possam ser transformadas em uma vol. 08, nº. 04, Número Especial. Rio de Janeiro, 2015.pp. 2493-2516 
Já no outro vértice do debate destacado, Agostinho observa a mesma questão por um ângulo diferente. Para o Bispo de Hipona, "nem todos os nossos desejos são voluntários, pois não temos acesso ao nosso ser inteiro; portanto, nossa conduta não é efeito unicamente da vontade. Não dominamos as forças que agem dentro de nós" (TODOROV, 2012, p. 29). Ou seja, a autonomia, em Agostinho, não é negada - em sua existência -, mas refutada como caminho possível para aquilo que é bom. Por isso, "na base de nossas pulsões inconscientes encontra-se a verdadeira fonte da impotência humana, que Agostinho chama de pecado original" (TODOROV, 2012, p. 29 - grifo nosso):

O pecado original é a opção pelo orgulho em detrimento da humildade, a rejeição às autoridades externas e o desejo de ser seu próprio senhor. Ao afirmar que os homens podem salvar-se a si mesmos, Pelágio reitera e glorifica o pecado original. [Por isso, para Agostinho,] nenhum homem pode ser libertado por seus esforços. No entanto, a salvação é possível, a impotência do homem não o condena a arder eternamente no inferno; o primeiro passo a ser dado consiste em abraçar a religião cristã [...] O passo seguinte consiste em submeter nossa conduta aos preceitos da Igreja: o que nos salva é a obediência, o que nos põe a perder é a aspiração a uma autonomia maior (TODOROV, 2012, p. 30 - grifo e colchetes nossos).

Como se pode depreender desta breve síntese do debate entre Pelágio e Agostinho, as implicações da discussão ultrapassam o limite das questões eminentemente teológicas. Afinal, é importante não perder de vista que, com Constantino, o Cristianismo é alçado à condição de religião oficial do Império Romano e, como vimos brevemente com Todorov (2012), o debate entre Agostinho e Pelágio ocorre, do ponto de vista histórico, quando o poder político se aproxima do religioso. Assim, nesta espécie de simbiose político-religiosa, submeter-se à Igreja - como quer Agostinho - implica, necessariamente, em submeter-se ao Estado. E divergir da primeira, consequentemente, significa agir contra o segundo. Nada mais natural, portanto, que Agostinho vencesse o debate: "Em 418, as ideias deste [Pelágio] são declaradas heréticas, seus discípulos são condenados, excomungados e expulsos; o próprio rastro de Pelágio se perde" (TODOROV, 2012, p. 32 - colchetes nossos).

Assim, as ideias de Agostinho, cujo núcleo central projetava a submissão e, consequentemente, a restrição da autonomia humana, colaboram para "[...] o lento processo de integração da romanitas há muito decadente com a christianitas já quase triunfante, reunidas depois para sempre, à sombra do poder, na era de Teodósio e Ambrósio [...] Começava, ali em Roma, a nascer a Europa Medieval" (DACANAL, 2013, 554 - grifo do autor).

Ou seja, as ideias agostinianas reforçam um poder espiritual já constituído, e agora intimamente ligado ao poder político, dando forma e legitimando o controle a partir da supressão da autonomia humana. Sem dúvida,

espécie de lei universal: "O imperativo categórico permite que o próprio indivíduo constitua um modelo universal de conduta, ou seja, uma lei moral”. A ideia fundamental da formulação, portanto, é a de que uma vontade racional é autônoma, livre para seguir suas próprias leis. Conforme BARTEL (2011, p. 43), "esta autonomia deve ser contemplada em uma legislação moral. Em outros termos, uma vontade racional é autolegisladora”. 
uma questão importante dentro da ortodoxia cristã ${ }^{10}$, mantendo a paz e a concórdia no Império, que se esfacelava diante de uma série de conflitos (DACANAL, 2013).

Contudo, se o dogma da Igreja de Roma passa a ser aquele legado por Agostinho, assentando o poder político-religioso da Europa Medieval a partir da supressão da autonomia dos indivíduos, o pensamento pelagiano não desaparece por completo. Segundo Todorov (2012), a partir da Renascença, autores profanos passam a se empenhar na defesa das capacidades humanas ${ }^{11}$, de modo que, no fim do século XVIII, ou seja, já nas Luzes,

[...] a herança pelagiana, revalorizada, sofre na sociedade francesa uma dupla transposição. De um lado, as pessoas se preocupam menos com o destino dos indivíduos e mais com o das sociedades; portanto, menos moral e mais política [Entretanto,] Ao deslocar-se do campo individual para o da coletividade, e ao libertar-se da moldura religiosa anterior, o projeto pelagiano se radicalizou. Impõe-se então a ideia de que a vontade humana, desde que se torne comum, pode fazer reinar o Bem e trazer a salvação a todos; e esse feliz acontecimento não se produzirá no Céu, após nossa morte, mas aqui e agora (TOROROV, 2012, p. 39-41; grifo e colchetes nossos).

Assim, é possível observar a inversão do debate central de fins da Antiguidade - que, por volta do século IV, favoreceu o poder político da Igreja - no século XVIII, influenciando, consequentemente, as revoluções liberais que, mais tarde, fundariam as sociedades democráticas no Ocidente. Contudo, importante observar que essa inversão, ao passo que tende ao resgate da autonomia dos indivíduos, também acena para uma forma irresistível de controle, em tese, sempre a serviço do Bem ou, de outro modo, sempre em nome da igualdade, da liberdade e da fraternidade que inspiram a própria Revolução Francesa, em 1789.

Por isso, Todorov (2012, p. 42 - destaque do autor), sugerindo uma espécie de maquiavelismo político na Revolução Francesa, pondera que, posto abaixo o Antigo Regime, ou seja, "conquistando o Bem, naturalmente será preciso empenhar-se em 'perpetuá-lo'. Em outras palavras: o uso da violência não pode parar. À revolução se seguirá o Terror, e este não decorre de circunstâncias fortuitas, mas da própria estrutura do projeto”. Ou seja, não há - como não havia antes, através da interpretação agostiniana - autonomia, dando margem a um enorme paradoxo frente à tensão contida entre liberdade e controle: se, antes, a Igreja apontava o único caminho, a própria Revolução Francesa resgata esses predicados da "antiga religião, tais como a fé cega nos novos dogmas, o fervor nos atos que the são úteis, o proselitismo dos fiéis, ou a transformação de seus partidários caídos em combate em mártires, figuras a adorar como se fossem santos" (TODOROV, 2012, p. 42).

\footnotetext{
${ }^{10}$ Segundo Dacanal (2013, p. 558-559 - grifo do autor; colchetes nossos), "ortodoxia em grego significa opinião verdadeira. Ou doutrina correta”. A relativa ao Cristianismo é fixada, ainda segundo este autor, em 325, no Concílio de Niceia, presidido por Constantino: "Foi a partir desta ortodoxia, ou doutrina correta, estabelecida em Niceia que o termo háiresis/heresia começou a perder o sentido original de escolha, opção ou preferência para adquirir o de erro ou desvio doutrinário. E, não raro, ça va sans dire [é evidente], também de dissidência política". Ou seja, o ponto de vista agostiniano, vencedor no debate com Pelágio, colabora para legitimar a já fixada ortodoxia cristã e, consequentemente, o poder político.

${ }^{11}$ Todorov (2012) cita Pico della Mirandola, autor do Discurso sobre a dignidade do homem (2006), Erasmo, do Elogio da Loucura (2003), Montaigne, conhecido por seus Ensaios (2010) e, na modernidade filosófica, Descartes, com seu Discurso do Método (2013).
} 
Assim, é possível observar uma singularidade que une ambos os momentos: se a ortodoxia cristã serviu ao propósito político de, ao retirar autonomia, manter a paz e, consequentemente, a coesão do Império Romano ${ }^{12}$, de igual modo a Revolução Francesa, espécie de embrião das sociedades democráticas, também sufocou os conflitos que se sucedem ao ato revolucionário em nome de uma causa maior. E, nesse sentido, impossível não relacionar esses acontecimentos à metáfora freudiana, contida em Totem e Tabu (2013), e à hipótese do paitirano, diante dos irmãos oprimidos e rebelados.

É o que se observa, a partir da análise de Enriquez (1990). Segundo este autor - ao debruçar-se à obra de Freud -, o chamado Tempo Primevo é composto apenas por relações de força, semelhante à metáfora hobbesiana de guerra de todos contra todos (HOBBES, 2009). Não há solidariedade. Esta, entretanto, surge a partir de um ato fundador, como o "big bang da civilização" (ENRIQUEZ, 1990, p. 30 - grifo nosso), quando os irmãos, reconhecidos entre si como tal a partir da impotência compartilhada frente ao pai, reúnem-se para partilhar o projeto comum ao grupo de matá-lo: "[...] o nascimento de um grupo é correlativo a um crime cometido em comum".

A partir da perspectiva freudiana, portanto, o grupo, o tecido social, a civilização, enfim, nasce de um crime - o assassinato do pai -, ato seminal que permite não apenas o reconhecimento dos irmãos enquanto semelhantes no projeto e no desejo de matar o pai, mas também permite a possibilidade de alteridade. Ou seja, o projeto do assassinado do pai oferece a unidade necessária, o sentimento comum ao grupo, enquanto a aniquilação da onipotência paterna permite, a partir do ódio e do contentamento compartilhados, saber o que se quer a partir daquilo que se rejeita. Entretanto, a morte daquele que causava a opressão não significa apenas a ausência da relação de força desigual entre o pai e os irmãos, mas, acima disso, a incorporação da força e da violência paterna pelos próprios irmãos, tornando, assim, "durável a existência do grupo" (ENRIQUEZ, 1990, p. $32)$.

Ora, não seria o Antigo Regime o próprio pai-tirano, e os revolucionários os irmãos que, ao eliminarem a fonte de opressão, passam a exercer o controle e a abafar os conflitos como mecanismos para manter o poder conquistado? Não seria a ortodoxia fixada por Constantino o próprio totem de um tabu ${ }^{13}$ - o pecado original -

\footnotetext{
${ }^{12}$ Segundo Dacanal (2013), o momento que precede o Concílio de Niceia é marcado por uma série de conflitos internos ao Império Romano. Entretanto, como bem ponderam Morais e Spengler (2012), os sistemas sociais não suportam a perpetuação do conflito. Por isso, ainda na esteira de Dacanal (2012, p. 558 - grifos do autor; colchetes nossos), "Constantino, um gênio político, identificara no cristianismo, em meteórica ascensão, a derradeira esperança da romanitas [... Mas] Constantino passara a exigir a contrapartida. E qual seria esta? Naturalmente, a colaboração ativa dos cristãos para manter a paz e a concórdia no Império".

${ }^{13}$ Embora Freud (2013, p. 62) acene para diferenças entre o tabu e as restrições religiosas, é importante atentar para o fato de que a ortodoxia fixada por Constantino foi, antes, uma imposição estratégica que se apropria do sagrado enquanto meio para um fim político. A partir dessa premissa, se for considerado o tabu como "uma série de restrições às quais esses povos primitivos se submetem; isto e aquilo são proibidos, eles não sabem por que e também não lhes ocorre perguntar a respeito, mas se submetem a elas como se fossem algo natural e estão convencidos de que uma transgressão será punida de maneira mais dura”, o conceito se relaciona com o ato que colabora decisivamente para legitimar esta mesma ortodoxia - o pecado original. Além disso, considerando o totem - ou o totenismo - como um sistema "que oferece a base para a organização social" (FREUD, 2013, p. 156), vol. 08, n. 04, Número Especial. Rio de Janeiro, 2015.pp. 2493-2516 2500
} 
fonte e legitimidade de toda a supressão da autonomia humana no Medievo, em nome da coesão da Europa sob as asas da Igreja?

Destes dois exemplos históricos - a Igreja no Medievo e a França Revolucionária - é possível observar a alteridade que permite o conflito sob dois enfoques: no primeiro, ela é necessária para produzir a ruptura, dar movimento ao tecido social; no segundo, ela deve ser coibida, eliminando a possibilidade de conflito para a própria manutenção do poder ou, ainda, a própria sequência do projeto de ruptura. Afinal como conclui Enriquez (1990, p. 358 - colchetes nossos), o assassinato do pai, ato que faz a passagem da horda ao Estado - ou ainda uma espécie de gênese do vínculo social - "é o que ao mesmo tempo pode conduzir à dissolução ou à sua [do grupo] destruição", já que o projeto comum, aquele que une os irmãos, depende de controle e submissão para manter a unidade criada. Por isso, "começam a funcionar os mecanismos de separação, de dominação, de exploração e de controle" (ENRIQUEZ, 1990, p. 358).

Desse modo, é possível concluir, portanto, que se o domínio da Igreja, que ocupa a posição deixada em aberto pelo Império Romano, responde pela coesão do Ocidente durante o Medievo, o modelo de organização social que se sucede ao declínio do poder papal, o Estado Moderno (BEDIN, 2008), depende, igualmente, de elementos de controle que garantam a manutenção do vínculo social. Nem mesmo o modelo liberal, que pôs abaixo o Antigo Regime, escapou a esta condição. Ao contrário, através do Terror, limitou as possibilidades de alteridade de forma absoluta, substituindo, entretanto, a ortodoxia religiosa pelo Direito, e dando, enfim, uma nova roupagem tanto ao totem quanto ao tabu freudianos.

Evidentemente, duas possibilidades se abrem diante da necessidade estatal: de um lado, o Estado, criação artificial voltada à organização da vida em sociedade, torna-se um fim em si, e sua existência serve aos propósitos de sua própria manutenção. Caso do Medievo e da França pós-revolução. O controle, nesse sentido, é absoluto, e sua maior expressão encontra, no século XX, eco nos chamados Estados totalitários. De outra banda, o Estado, ao manter o monopólio da jurisdição, busca, através dela, equilibrar as pulsões individuais de autonomia frente à necessidade de coesão do tecido social. São, em linhas gerais, os Estados considerados democráticos.

\section{A FUNÇÃO SOCIAL DO CONFLITO E AS FORMAS DE CONTROLE NO TOTALITARISMO}

Em que pese a significação eminentemente negativa da palavra conflito no senso comum, este corresponde não apenas ao princípio dos vínculos sociais - como visto, a partir da perspectiva freudiana -, mas também a uma importante possibilidade de ação que permite, através da capacidade de alteridade dos indivíduos,

a ortodoxia cristã, fixada por Constantino no Concílio de Niceia - ou mesmo a própria Igreja, enquanto guardiã do dogma -, pode, igualmente, ser associada ao totem. 
projetar novas condições a partir de determinadas necessidades. O conflito é, do ponto de vista das sociedades, aquilo que permite, portanto, o movimento.

Buscando uma conceituação mais detalhada para conflito, Morais e Spengler (2012, p. 45) ponderam que este “[...] consiste em um enfrentamento entre dois seres ou grupos da mesma espécie que manifestam, uns a respeito dos outros, uma intenção hostil, geralmente com relação a um direito". Ainda para estes autores, o conflito pode ser definido a partir de três pressupostos considerados fundamentais:

[...] posse individual de interesses de base que cada um procura realizar e que são peculiares a cada sociedade, [...] necessária ênfase sobre o poder como núcleo das estruturas e realizações sociais e na luta para obtê-lo, e, por fim, as ideias e valores utilizados pelos mais diversos grupos sociais como instrumentos para definir sua identidade e seus objetivos (MORAIS E SPENGLER, 2012, p. 47).

Assim, diante destas características, o conflito pode ser observado não apenas como algo inerente ao homem, mas, também, como um importante mecanismo de interação social que faculta o movimento, possibilitando, assim, “[...] elaborações evolutivas e retroativas no concernente a instituições [...] O conflito pode ser classificado como um processo dinâmico de interação humana e confronto de poder no qual uma parte influencia e qualifica o movimento da outra” (MORAIS E SPENGLER, 2012, p. 47-48).

Desse modo, é possível entender o conflito, por um lado, como inevitável. E, por outro, como algo importante - sobretudo nas democracias, diante de uma essência necessariamente plural. Nesse contexto, fundamental, portanto, é compreender os meios necessários para manejá-lo. Afinal, uma sociedade sem conflitos, como já assinalado anteriormente, é estática (MORAIS E SPENGLER, 2012).

Nesse mesmo sentido, Georg Simmel (1983) resume a importância sociológica do conflito, afirmando que, assim como o universo precisa de amor e ódio, de forças de atração e de forças de repulsão para que tenha uma forma qualquer, também a sociedade, para alcançar uma determinada configuração, precisa de quantidades proporcionais de harmonia e desarmonia, de associação e de competição, de tendências favoráveis e desfavoráveis. Sociedades definidas, verdadeiras, não resultam apenas nas forças sociais positivas da inexistência de fatores negativos que possam atrapalhar. A sociedade, tal como se a conhece, é o resultado de ambas as categorias de interação - positivas e negativas -, que se manifestam desse modo como inteiramente positivas.

Por isso mesmo, como bem pontuam Simmel (1983), Morais e Spengler (2012), é possível afirmar que o conflito - ou a dinâmica conflitiva - é um mecanismo capaz de manter a vida em sociedade, determinar o futuro e promover a alternância de usos e costumes, valorizando certas posturas e outras não. Assim, o conflito pode ser tanto negativo quanto positivo, e sua valoração - ou seja, a qualidade de positivo ou de negativo - estará relacionada à legitimidade das causas em que ele se dará e ao modo como será administrado.

Entretanto, ao passo em que as sociedades foram ficando cada vez mais complexas, uma normatização mínima - voltada não apenas para promover o convívio, mas, sobretudo, também para assegurar a sobrevivência 
do Estado em si - surgiu, acompanhada, evidentemente, por instrumentos para que tais normas fossem respeitadas.

Contudo, se o conflito é, resumidamente, a condição para o movimento social e, ao mesmo tempo, a ação insuportável à manutenção da organização estatal ${ }^{14}$, e seu produto é, como bem pontuam Morais e Spengler (2012), a diferença obtida pela subtração do poder mais fraco pelo mais forte, infere-se a necessidade de um certo equilíbrio normativo na regulação dessas tensões, de modo que: a) o conflito permita o movimento necessário ao desenvolvimento social; b) o conflito não rompa a frágil malha do tecido social e c) o conflito não permita aos mais fortes subjugar os mais fracos, considerando, ao menos, uma igualdade formal entre os indivíduos.

Posta assim a questão, o problema, portanto, passa a ser: quem diz o equilíbrio?

A resposta passa, necessariamente, pela organização do grupo, que, desde as heranças históricas que formaram o Ocidente - ou seja, muito antes das formas políticas consideradas modernas, surgidas a partir do fim do Medievo (BEDIN, 2008) -, impõe um mínimo valorativo voltado à vida em sociedade. Através da lição de Morais e Spengler (2012), esse mínimo pode ser observado sempre em relação a um papel social, ou seja, a uma forma de comportamento pré-determinada e que, necessariamente, deve ser assegurada. Assim, àqueles que observam com correção o seu papel, há recompensa ou, pelo menos, ausência de punição. E, àqueles que não observam, castigo ou privação ${ }^{15}$.

Conforme Chasin (1977), é possível observar equilíbrio - ou, pelo menos, cercar-se de elementos voltados a promovê-lo - nas relações conflitivas e na pré-determinação de papeis sociais no Estado Liberal. Afinal, "[...] o estado liberal vem a ser o sistema no qual predominam a lei, a razão e a liberdade, garantidas pela difusão do poder e pela estrutura pluripartidária” ${ }^{16}$ (CHASIN, 1977, p. 01 - grifo do autor).

De outra banda, esse mesmo autor aponta para a antítese desta forma política: o totalitarismo, ou seja, o modelo que inverte as predisposições do Estado Liberal e, consequentemente, altera o equilíbrio anteriormente referido. O Estado passa a ser, dessa maneira, um fim em si, sistematizando as alteridades até então existentes (LACLAU E MOUFFE, 1985). Já Sakamoto (2012) não parte exatamente de uma inversão, mas de uma

\footnotetext{
${ }^{14}$ Conforme Morais e Spengler (2012), o Estado não suporta a perpetuação do conflito. E, nesse sentido, vale recordar os exemplos da Igreja no Medievo e o da França pós-revolução. Os núcleos de poder asseguram sua manutenção através do controle que, em tese, voltava-se contra qualquer possibilidade de contestação ou divergência.

${ }^{15}$ Em Marx (1996), são os fatores econômicos que determinam a estrutura social, e o equilíbrio social é produto do jogo de conflitos - aqui, obrigatoriamente de raiz econômica, portanto -, das relações de poder exercidas pelo Estado no tratamento de conflitos, que ocorrem como um instrumento de domínio de classes. Já em Weber (1981), a efetivação de determinadas regras é fruto da racionalização da sociedade moderna, da tradição ou do carisma do líder e, portanto, as relações de poder do Estado não predizem apenas o uso da força, mas o uso da força legítima. Dessa maneira, para Weber, o Estado mantém a coesão social. De igual modo, Dahrendorf, segundo Moraes e Spengler (2012), aponta dois caminhos: 1) a ordem social como produto de um acordo geral; 2) coesão e ordem como frutos de coerção e força. Entretanto, como um enfoque não exclui o outro, e a autoridade é um poder legítimo, o Estado pode mediar os conflitos.

${ }^{16}$ Nesse mesmo sentido, Lefort (1991) acena para esta forma política como aquela que permite ao Estado moldar e ser, ao mesmo tempo, moldado pela sociedade. Para este autor, outra importante característica é o lugar do poder, sempre vazio, e sujeito à sorte do grande número, ou seja, intimamente vinculado à pluralidade de pontos de vista.
} 
destruição, de modo que o fenômeno totalitário se dá em uma espécie de vácuo social. Ou seja, para seu surgimento, é fundamental que determinados traços culturais não estejam mais presentes no grupo. Afinal, "O totalitarismo é o governo que cria instituições políticas inteiramente novas destruindo todas as tradições sociais, legais e políticas do país. Este domínio pretende eliminar todo fundamento da individualidade humana ao destruir as relações entre os cidadãos" (SAKAMOTO, 2012, p. 60).

No século XX, essa destruição - voltada, sobretudo, à transformação da natureza humana (ARENDT, 2012) - passou, paradoxalmente, pelo esfacelamento da autoridade ${ }^{17}$ que, segundo esta mesma autora ${ }^{18}$, foi, no princípio, conectada com a tradição romana e com a religião. Ou seja, conectada a, pelo menos, dois dos três pilares que deram forma ao Ocidente ${ }^{19}$. Assim...

No lugar da autoridade surgiu o senso comum: o senso comum era supostamente baseado no interesse. O que me fazia me ajustar a um mundo comum e o que me fazia me ajustar politicamente eram os interesses, que estavam entre nós e nos mantinham juntos como um grupo. O que governava agora, na formulação de Rohan ${ }^{20}$, era o interesse que comanda os reis. O senso comum era, em segundo lugar, a quintessência dos comumente aceitos padrões de certo e errado e critérios de julgamento sob os quais posso subsumir o particular. Esses eram novamente comuns a todos os que viviam em uma mesma comunidade. Eles dependiam do mundo comum. Falência do senso comum: a ascensão das massas demoliu o interesse - as massas, distintamente das classes, consistem de indivíduos que nada têm em comum, nenhum mundo comum, nenhum interesse comum. Em segundo lugar veio a falência de nossos critérios de julgamento que, embora não soubéssemos, repousavam em conceitos utilitários de interesse. A falência do senso comum é apenas outra expressão para a falência do mundo comum, que é o mundo político propriamente dito. $O$ mundo no qual vivemos é caracterizado pelo fato de que não podemos depender de autoridade alguma nem de nosso senso comum para compreendê-lo. O totalitarismo é, em muitos aspectos, a resposta precisa a esta perplexidade (ARENDT, 2011, p. 231).

A partir da análise desta autora, é possível compreender, portanto, que o fenômeno totalitário não é, nos meios, um projeto de gênese eminentemente política, mas, antes disso, um desdobramento do social - assim como o Direito, vinculado a condições e necessidades históricas - cujos fins são canalizados para um poder hegemônico, que recusa a alteridade, mas, ao mesmo tempo, dela depende. Afinal, como bem observa Mendonça (2007, p. 251 - parênteses e destaque do autor) ao debruçar-se à obra de Laclau:

A hegemonia é uma relação em que uma determinada identidade, num determinado contexto histórico, de forma precária e contingente, passa a representar, a partir de uma relação equivalencial, múltiplas identidades. A ideia de hegemonia existe justamente em contraposição à ideia de falta constitutiva presente na teoria laclauniana. A noção de falta constitutiva induz a ideia de que todas as identidades se constituem sempre de forma

\footnotetext{
${ }^{17}$ Para Arendt (2011), a autoridade não se confunde com o fenômeno totalitário, pois, no último, se presume a violência como forma de dominação.

${ }^{18}$ Segundo Correia (2011), tal ponto de vista foi trazido à luz em uma palestra no Oberlin College, em 1954, ou seja, entre a publicação de As origens do totalitarismo, em 1951, e A condição humana, em 1958.

${ }^{19}$ Como observado ainda na Introdução deste estudo, o Ocidente foi formado a partir do pensamento helênico, da política romana e da religião judaico-cristã (DACANAL, 2012).

${ }^{20}$ Referindo-se, de acordo com Correia (2011), à obra De l'intérêt des princes et états de la chrétienté, de 1638, dedicada pelo conde de Rohan ao cardeal Richelieu.
} 
incompleta, seja em função da sua própria articulação incompleta de sentidos, seja a partir de sua relação com outras identidades, seja, ainda, por sua negação a partir de seu corte antagônico (uma outra identidade que nega sua própria constituição). No sentido de Laclau, portanto, toda identidade vive numa constante busca à completude, sendo tal busca, contudo, sempre ineficaz. A hegemonia, in contrario sensu à noção de falta constitutiva ou de incompletude identitária, visa a preencher essa ausência de plenitude.

Assumindo posição universalizante diante de identidades que se formam de maneira incompleta, o discurso hegemônico, portanto, preenche o vazio identitário, reduzindo, assim, “[...] a infinita pluralidade e diversidade dos seres humanos como se toda a humanidade fosse apenas um indivíduo" (SAKAMOTO, 2012, p. 62). E, justamente por isso - por reduzir a pluralidade e diversidade típicas do humano - o totalitarismo, como bem pontua Arendt (2012), é voltado à transformação da natureza humana. Ou seja, independente da forma nazismo, stalinismo ou, mais recentemente, Estado Islâmico, por exemplo, entre outras possibilidades totalitárias , o núcleo duro do totalitarismo é a aniquilação da individualidade, tendendo, invariavelmente, a sufocar os conflitos, anteriormente percebidos como necessários.

Interessante, nesse sentido, as observações de Dahrendorf (1992, p. 165), ao pontuar que uma das formas de individualidade, aquela atrelada à redescoberta da etnia, foi um passo adiante no processo de civilização, pois significou uma "compreensão incipiente de que os direitos comuns de cidadania não estão em conflito com as distinções culturais, mas, ao contrário, dão a elas um novo alcance. Mas a feliz harmonia não durou muito. Em muitos lugares, as diferenças passaram a ser usadas como armas contra a cidadania”.

As observações deste autor trazem à mente - conforme ele mesmo menciona - a questão da modernidade e das ligaduras. Segundo Dahrendorf, "em alguns aspectos o mundo moderno pode parecer um lugar frio que abre oportunidades através da ruptura dos laços sem os quais é difícil viver". E vai além:

[...] muitos deles têm um aspecto em comum que é diretamente relevante para o conflito social moderno em torno da cidadania e das chances da vida. Eles são um ataque contra as forças civilizadoras da cidadania em nome de direitos de minorias, ou de autonomia cultural, religiosa ou étnica. E o que é pior, as próprias pessoas que deveriam ter mais consciência por terem lutado por cidadania no passado são, ao menos em parte, responsáveis pelo sucesso desse ataque (DAHRENDORF, 1992, p.165-166).

Esse é um grande retrocesso na historia da sociedade civil, e custa caro. O custo é, em primeira instância, o de conflitos que desafiam qualquer solução, e que por isso fogem aos limites estatais para o seu tratamento. Talvez porque esses conflitos não observem a alteridade contida nos envolvidos, funcionando com uma lógica totalitária que, ao evitá-la, não reconhece o que há de humano nos seres humanos.

Por mais paradoxal que seja, tal lógica totalitária, ao tentar reduzir o grupo, nos dizeres de Sakamoto (2012, p. 62), "à mesma identidade de reações”, admite a capacidade de alteridade do ser humano como uma qualidade que o forma em essência, ou seja, como um princípio ontológico que permite classificar o humano enquanto humano. Por isso, impossível não relacionar a abordagem de Arendt (2012) - transformação da 
natureza humana - à Oceânia de 1984²1, de George Orwell (2009), habitada por seres automatizados, sufocados pelo controle do Partido, sem qualquer possibilidade de alteridade. Ou seja, não humanos sem possibilidade alguma de liberdade. Afinal, como observa Milovic (2007, p. 389 - grifo nosso), "[...] a emancipação é uma possibilidade da racionalidade", e não de um consenso imposto de cima para baixo.

Se a ficção orwelliana - entre outros, como Nós, de Zamyatin (2014), e Admirável mundo novo, de Huxley $(2014)^{22}$-, caminha nesse sentido, qual seja, o da supressão da autonomia, da racionalidade e da subjetividade e, consequentemente, da supressão também do político - a História mostra sistemas, como a Alemanha de Hitler ou a União Soviética de Stálin, por exemplo, igualmente voltados a “[...] controlar a vida privada de seus cidadãos a ponto de torná-los, compulsoriamente, 'reeducados' para passar o resto de suas vidas sob o regime" (SAKAMOTO, 2012, p. 64 - destaque do autor).

Assim, como observado recentemente, a supressão da capacidade de alteridade - ou a transformação desta qualidade ontológica do ser humano -, buscando a redução da pluralidade contida em um determinado grupo em nome de uma unidade coesa, evidentemente abafa, por seu turno, os conflitos. Afinal, como divergir, se o grupo está reduzido a uma mesma identidade? Ou ainda: como a diferença pode ser possível dentro deste modelo?

As respostas, evidentemente, são negativas. Afinal, se não há alteridade, não há, também, racionalidade que permita uma teoria voltada a problematizar o sistema totalitário, ou seja, voltada a qualquer possibilidade de emancipação. Não há, em outras palavras, um caminhar histórico semelhante àquele trilhado pelos Direitos Humanos (BOBBIO, 2004), formado por condições e necessidades próprias de um determinado tempo. Não há, enfim, movimento; tudo é, portanto, estático.

Essa condição de inércia, contudo, compreendida não apenas como objeto do totalitarismo, mas, antes disso, como elemento fundamental para o seu próprio surgimento diante do vácuo social observado por Arendt (2011), também é uma forma de esterilização política. Afinal, como bem pontua Milovic (2007, p. 390), ao debruçar-se à obra desta autora, "[...] não existe uma identidade originária da política, nós não somos seres políticos por natureza". Ou seja, se a política é uma possibilidade - e não uma obrigatoriedade - de interação, limitar a capacidade - ou a qualidade ontológica do ser humano - de alteridade significa, portanto, uma forma de não política - onde, em tese, o conflito não é possível, e a paz, quando obtida, é determinada pela imposição do

\footnotetext{
${ }^{21}$ Publicado originalmente em 1949, o livro de Orwell (2009) retrata uma nação fictícia, Oceânia, cujo destino é determinado por um Partido - com inicial maiúscula, propositalmente, por ser o único. Nessa sociedade totalitária, pensar de forma diversa é considerado um crime gravíssimo.

${ }^{22}$ Para Fromm (2009), em pósfacio à ficção de Orwell, estas duas obras formam, junto com 1984, uma trilogia de utopias negativas, em que se evidencia o desespero diante dos caminhos percorridos - ou a percorrer - pelo homem. Em todas elas, as sociedades são automatizadas. São obras, segundo esta interpretação, opostas às chamadas utopias positivas, que davam ênfase às potencialidades do homem, rumo a um mundo melhor, típicas do Humanismo.
} 
consenso. Essa paz, pelos meios de sua obtenção, portanto, não é estável, já que seu saldo, ao sufocar os conflitos, abre mão da competição:

Mouffe ${ }^{23}$, inclusive, fala sobre os perigos de uma teoria que procura as soluções consensuais e, assim, marginaliza os verdadeiros conflitos. Pensei, neste contexto, no meu país, exYogoslavia, cujo conflito também pode ser melhor entendido dentro dessa reconstrução de Chantal Mouffe. O comunismo postulou um certo consenso, a solidariedade ou irmandade dos povos dentro do universal projeto da sua realização. Assim, os verdadeiros conflitos entre os povos nunca chegaram à articulação política. Depois da morte de Tito, o conflito aberto apareceu. $\mathrm{O}$ governo dele não conseguiu, nas palavras de Mouffe, transformar o antagonismo no agonismo ${ }^{24}$, transformar o conflito numa competição política (MILOVIC, 2007 , p. 392 - grifo nosso).

Daí Ralf Dahrendorf (1991, p. 20) concluir, na prática, que o conflito social é indispensável à democracia, e tanto mais saudável quanto mais apta a canalizá-lo produtivamente, do ponto de vista de emulação econômica e de circulação das elites. Assim, ainda segundo este autor, todos os sistemas e mudanças sociais têm o conflito como fulcro, nele encontrado seu motor e seu regulador. Daí também a repulsa de Dahrendorf às utopias de sociedades sem classes e sem conflitos. Utopias imobilizantes do progresso histórico, só embasadas, a seu ver, na competição resolvida pelo conflito. "Os conflitos devem ser institucionalizados e não ocultos".

Por isso, ao se impor uma verdade à margem do conflito, determinando, portanto, um consenso longe da arena política, palco, em tese, onde o próprio conflito transforma-se em competição, as tensões contidas na Yogoslavia de Tito, por exemplo, permaneceram. Ou seja, se podemos considerar o status do grupo como o vinculado ao próprio conflito, o exemplo do Milovic (2007), associado à lição de Dahrendorf (1991) demonstra, claramente, a condição estática típica do fenômeno totalitário: em um dado momento, as tensões tornaram-se, novamente, visíveis.

\section{AS DEMOCRACIAS PODEM SER TOTALITÁRIAS?}

Em que pese a inegável proximidade não apenas do exemplo yogoslavo, visto recentemente, mas de todas as características anteriormente analisadas em relação às formas totalitárias, para responder à pergunta que abre a última parte deste estudo é importante não perder de vista que, como vimos com Arendt (2011), o fenômeno totalitário se dá a partir de uma espécie de vácuo social, proposto, inicialmente, diante do esfacelamento da autoridade. Também conforme procuramos demonstrar através do pensamento desta autora, não apenas a chamada tradição - que funda o Ocidente - mas também o próprio senso comum - enquanto fonte

\footnotetext{
${ }^{23}$ Referindo-se à filósofa política belga Chantal Mouffe.

${ }^{24}$ Morais e Spengler (2012), ao ponderar sobre o estado agonal, observam que a principal característica deste é não perceber as partes de um conflito como inimigas, mas, sim, como competidores. De igual modo, Mouffe (2005, p. 11 - destaque da autora), salienta, igualmente, que “[...] a partir da óptica do 'pluralismo agonístico', o propósito da política democrática é construir o 'eles' de tal modo que não sejam percebidos como inimigos a serem destruídos, mas como adversários, ou seja, pessoas cujas ideias são combatidas, mas cujo direito de defender tais ideias não é colocado em questão".
} 
de autoridade ou, pelo menos, enquanto elo para um mundo em comum - foram deteriorados, contribuindo para esta espécie de vácuo.

Nesse mesmo sentido, Milovic (2007), ao recuperar a discussão da Modernidade que se inaugura com o pensamento de Descartes (2013), acena para uma forma de pensar capaz de romper com a Tradição e o senso comum - abrindo margem aos pressupostos observados por Arendt (2011) -, mas encerrada no seu próprio paradigma: o pensar o mundo como fato.

Pensar o mundo como fato [entretanto] significa pensar a estática do mundo. Significa, em outras palavras, não pensar as alternativas, não pensar o novo [...] O interesse cartesiano ficou ligado ao mundo, com a prova do mundo e não com a perspectiva do ego. Poderia ser uma outra Modernidade que, desde o início, criasse a resistência contra as formas posteriores de ideologia [...] Pensar só os fatos, em último momento, significa não sair do sistema existente, inclusive do sistema social e político atual (MILOVIC, 2007, p. 380-386 - colchetes nossos).

Por sua vez, Todorov (2012) percebe, nesta forma de ver e pensar o mundo, a tônica do pensamento que embasa - junto ao pelagianismo - a Revolução Francesa, evento que, conforme a lição de Lefort (1991), é considerado como um dos pilares do Estado Liberal, modelo adotado, ainda segundo este autor, nas sociedades ditas ocidentais.

Assim, pondera Todorov (2012), o cientificismo que passa a moldar o pensamento ocidental, influenciando decisivamente a concepção política, projeta - não apenas ao estudo dos corpos, mas à vida social leis naturais, ou seja, leis apenas passíveis de serem descobertas, mas jamais criadas. Citando os Princípios da Política, de Benjamin Constant, este autor evidencia a questão: "Não sendo as leis mais do que a expressão das relações existentes entre os homens, e sendo essas relações determinadas pela natureza deles, ninguém pode fazer uma lei nova, mas somente uma declaração nova daquilo que existia precedentemente" (TODOROV, 2012, p. 93).

Estreitando, portanto, o campo da ação política - ou seja, do conflito transformado em competição - ao projetar às relações sociais um conjunto de leis naturais, o pensamento revolucionário aproxima-se, paradoxalmente, dos ideais agostinianos que sustentaram o poder - do Medievo aos Estados dos Reis, assentados em uma pretensa natureza divina - propondo uma condição que, também dada pela natureza, seria imutável.

Mas, afinal, essa forma de pensar o mundo, possibilitada pela Modernidade inaugurada com Descartes (MILOVIC, 2007) e assimilada, portanto, pelo Liberalismo, cuja própria defesa da liberdade é também assentada em uma natureza imutável das relações sociais, não projeta um mundo tão estático quanto o que se propôs pôr abaixo? Em outras palavras: O esfacelamento da Tradição e do senso comum observado por Arendt (2011) não seria, antes, apenas uma nova roupagem para essa mesma Tradição e esse mesmo senso comum? 
Todorov (2012) não esboça uma resposta específica a essas questões, mas, através das aproximações feitas por este autor - entre o totalitarismo e o liberalismo que desenha politicamente as sociedades ocidentais permite observar pontos tão comuns quanto opacos entre um e outro.

E, nesse sentido, conforme o pensamento deste autor, ao passo que as sociedades liberais se empenharam em abolir o lugar do poder como um espaço de significação privada, projetando uma arena em que a competição, em tese, renovaria periodicamente a instância do próprio poder, essa mesma concepção ancorou seus ideais na defesa das liberdades civis, políticas e econômicas. Estas, invariavelmente observadas como parte das relações humanas - naturais, portanto -, igualmente não poderiam ser objeto do novo, mas, sim, partes de um todo, sempre existente, apenas tornado visível - quase como uma revelação - a partir da Revolução. Afinal, como vimos, não havia, na gênese do pensamento liberal, a possibilidade de se projetar nada além do que, precedentemente, já existia.

Ou seja, embora pareçam válidas as críticas liberais acerca do totalitarismo no século XX - ou, ainda, as feitas pelos revolucionários em relação ao Antigo Regime - o núcleo duro de ambos é o mesmo: há uma natureza não apenas das coisas, mas da vida social, e essa natureza, percebida pelas lentes próprias da mecânica do cientificismo, corresponde a uma lei imutável. A diferença de pensamento, portanto, é apenas uma: a natureza das coisas e das relações humanas é percebida de maneira inversa; o que é válido e objeto de defesa intransigente para uns é, ao mesmo tempo, falso e objeto de repúdio para outros. Mas, ainda assim, são possibilidades e visões de mundo acima do conflito ou, em se tratando de política, acima da competição, negando, portanto, qualquer possibilidade de alteridade. Afinal, ambas as possibilidades são, na ótica de cada grupo, naturais e, portanto, imutáveis, acima da discussão.

Assim, imperioso observar que a inversão proposta, sob a égide da liberdade, impõe, paradoxalmente, uma condição social tão engessada quanto antes - e, ao mesmo tempo, tão próxima do fenômeno totalitário, surgido em meados do século XX -, justamente - e, mais uma vez, paradoxalmente - pela ausência de controle que a própria defesa da liberdade sinaliza: se no Antigo Regime não havia formas negativas de controle estatal, e os governos se colocavam acima das leis, ou, se nos modelos totalitários, o governo incorpora a própria lei, confundindo-se com ela e, igualmente, dotando-se, por sua vez, de poderes ilimitados, o Liberalismo, da mesma forma, projeta um poder formidável a partir da própria liberdade. Enquanto as liberdades civis e políticas - que jamais podem ser observadas como vazias de significado - contribuem para o esfacelamento do senso comum ou do elo de um mundo comum, como pontua Arendt (2011) - as liberdades econômicas projetam, sobretudo, uma forma de poder tão absoluto quanto o do Antigo Regime ou aquele observado no fenômeno totalitário.

Afinal:

[...] a economia, tornada global, já não está submetida ao controle político dos Estados; muito ao contrário, foram os Estados que se colocaram a serviço dela. De fato, estes últimos 
estão submetidos às agências privadas de classificação de riscos, que orientam suas escolhas, enquanto elas mesmas escapam a qualquer poder político. De democracia, eles já não têm senão o nome - não é mais o povo que detém o poder [...] Em cada país, a ideologia ultraliberal ${ }^{25}$ tampouco deixa muito espaço para a ação política (TORODOV, 2012, p. 104).

Para este autor, o modelo favorece, portanto:

[...] a constituição de oligarquias político-econômicas, [cuja soberania é encarnada na] vontade dos indivíduos, acima da soberania política, seja qual for a sua natureza. Ao fazer isso, infringe - paradoxalmente - o princípio fundador do pensamento liberal, que é a limitação de um poder pelo outro. O liberalismo clássico se baseia na heterogeneidade do corpo social: como o interesse comum nem sempre coincide com os interesses particulares, ele quer limitar a ação da vontade geral pela defesa das liberdades individuais, e reciprocamente (TODOROV, 2012, p. 105).

De igual modo, também buscando pontos de aproximação entre democracia e totalitarismo, Lefort (1991, p. 35), por sua vez, questiona: “[...] a democracia já não dá lugar a instituições, a modos de organização e de representação totalitária?". A questão, que em si já guarda a possibilidade dos traços necessários à constituição de um "novo despotismo" (LEFORT, 1991, p. 31; grifo nosso), tem como resposta do próprio autor um aceno positivo, mas, ao mesmo tempo, contendo também um importante contraponto - aqui considerado decisivo - à análise de Todorov (2012). Diz este autor:

Com frequência, afirma-se hoje só haver uma diferença de graus de opressão entre democracia e sistema totalitário. Melhor ainda: alguns comprazem-se em 'democracia totalitária' [...] Por certo, temos boas razões para considerar que a evolução das sociedades democráticas tornou possível o aparecimento de um novo sistema de dominação [...] Mas, ao menos é necessário reconhecer que a formação desse sistema implica a ruína da democracia; a formação desse sistema não fornece uma conclusão para a aventura histórica que a democracia introduziu ${ }^{26}$ : muda seu sentido. As ambiguidades de democracia não desaparecem com a realização de uma dessas tendências, a tendência que dota de uma força cada vez maior o aparelho do Estado, pois este encontra-se desmantelado em favor do aparelho do Partido, cujo objetivo não é absolutamente o de assegurar o bem-estar dos cidadãos. Que não nos cansemos de mediar sobre esse fato: o totalitarismo não marca somente a destruição da liberdade política, também destrói a dinâmica da potência tutelar ou do Estado-Providência. Sejam quais forem os traços do novo regime - fascista, nazista ou stalinista, que se instale no rastro do socialismo soviético ou sob a atração desse modelo na Europa, na China, na Coreia, no Vietnã, ou em Cuba -, não é o princípio do bem-estar que orienta o desenvolvimento do Estado (LEFORT, 1991, P. 45-46 - destaque do autor).

Assim, pelos princípios ontológicos que formam, em essência, tanto democracia quanto totalitarismo, não é possível pensar o fenômeno totalitário dentro do regime democrático. Isso, entretanto, não anula os pontos de aproximação entre um e outro, sobretudo no que se refere à competição na arena política. Afinal, como bem observa Todorov (2012), o cientificismo de que se revestiu o Liberalismo, herança moderna que permanece na

\footnotetext{
${ }^{25}$ Para Todorov (2012), o termo ultraliberal corresponde à atual fase do Liberalismo Clássico surgido no século XVIII. O termo neoliberal, por sua vez, também corresponde ao Liberalismo Clássico, mas já apresentando algumas diferenças em função do avanço comunista, sobretudo a partir de 1917, na Rússia.

${ }^{26}$ Conforme Lefort (1991, p. 31 - grifo do autor), a democracia é uma construção social histórica, enquanto o totalitarismo, por seu turno, não: "A democracia revela-se assim a sociedade histórica por excelência, sociedade que, por sua forma, acolhe e preserva a indeterminação, em contraste notável com o totalitarismo que, edificando-se sob o signo da criação do novo homem, na realidade agencia-se contra essa indeterminação, pretende deter a lei de sua organização e de seu desenvolvimento, e se delineia secretamente no mundo moderno enquanto sociedade sem história”.
} 
atualidade, também é uma forma de se engessar o pensamento e fechar-se ao novo, suprimindo - ou abafando os conflitos. É, evidentemente, um caminho que não se compartilha com o totalitarismo, mas, ainda assim, objeto de atenção. Afinal, como ensaia Milovic (2007, p. 393):

O caminho do consenso que esconde os conflitos é uma ilusão perigosa. Do mundo desapareceram os antagonismos, entre a esquerda e a direita, por exemplo. É de interesse vital abandonar a referência à possibilidade de consenso e deixar o espaço democrático aberto [...] Poderíamos dizer que a democracia é só um projeto. Um projeto que talvez chegue.

De fato, por fim, a idealidade democrática - ou o projeto de Milovic (2007) - ainda está longe da realidade democrática. Contudo, essa mesma realidade - embora se aproxime, flertando com o fenômeno totalitário - tem, em sua própria gênese histórica e nas indeterminações que a formam, os condicionantes fundamentais para a efetivação deste mesmo projeto que, por ser também histórico, nunca estará pronto. Ou seja, a democracia, pela própria natureza, é um projeto sempre aberto, sujeito, portanto, a toda sorte de indeterminismos. Inclusive negativos.

\section{CONCLUSÃO}

Conforme observado neste estudo, o conflito não é apenas uma forma - entre tantas - de interação social, mas, acima disso, uma possibilidade de movimento ao grupo. Através do mito freudiano, analisado também como o momento seminal de formação do social, evidenciou-se, além da condição de movimento, outra singularidade a partir do conflito: a necessidade de controle para manter a unidade do grupo. Assim, é possível concluir, inicialmente, que os conflitos são positivos à medida que promovem o movimento frente à alteridade dos indivíduos que compõem o grupo, e negativos à medida que se revelam como combates desordenados, colocando em xeque a coesão do tecido social. O controle, inevitável, deve primar, portanto, pelo equilíbrio.

Esse mesmo controle, por sua vez, se opõe e se liga - em maior ou menor grau - diretamente à autonomia dos indivíduos. Dois momentos históricos - considerados aqui marcos importantes, cujas heranças são legados à contemporaneidade - foram dados nesse sentido: o primeiro refere-se à aproximação da Igreja ao poder político no período que assinala a transição do Mundo Antigo para o Medievo. Neste exemplo, foi observado como o discurso teológico rompeu as barreiras do sagrado, assentando as bases para uma forma de controle eminentemente política por toda a Europa. Já no segundo exemplo, o da Revolução Francesa, pôde ser analisado como o mesmo discurso teológico fora invertido, permitindo pôr abaixo todo um sistema e, ao mesmo tempo, exercendo, ainda, uma brutal forma de controle sobre os indivíduos, ou seja, encerrando, em si, um grande paradoxo.

Esses dois momentos históricos, contudo, não apenas acenam positivamente à hipótese freudiana do pai-tirano e dos irmãos oprimidos, mas, acima disso, demonstram, à luz desses fatos históricos, os efeitos do 
controle absoluto da autonomia humana: no Medievo, é possível considerar aproximadamente dez séculos de uma forma de sociabilidade totalmente estática; na Revolução Francesa, o próprio Terror.

Evidentemente, as mesmas discussões em torno da autonomia humana - necessária à alteridade e, portando, ao próprio conflito -, tanto no Medievo quanto na França Revolucionária, chegaram à contemporaneidade. Os grandes exemplos negativos - ou, ainda, os grandes exemplos de desequilíbrio absoluto em favor do controle - são os regimes totalitários que se seguiram no século XX, sobretudo, no pós-guerra.

São, como observado, regimes que negam de maneira intransigente qualquer possibilidade de autonomia das pessoas - e, por isso, é impossível falar de indivíduo -, suprimindo o conflito - ou a competição na arena política - em nome da unidade do grupo. Os Estados, diante do fenômeno totalitário, são confundidos com o Partido dirigente. Não há pluralidade, e as pessoas são reduzidas à mesma unidade de sentido. São, portanto, sociedades estáticas e à margem da própria História: não há movimento que permita o surgimento de condicionantes ou circunstâncias históricas em favor da dinamicidade do grupo.

Contudo, mesmo à margem da História, o fenômeno totalitário surge a partir dos indeterminismos - tão típicos da democracia - observados na própria História, além, é claro, das identidades sempre incompletas. Afinal, o totalitarismo flerta com um determinado grupo a partir do esfacelamento dos vínculos de autoridade - como através da chamada Tradição e do senso comum - que, em tese, ofereciam, em maior ou menor grau, um mínimo valorativo, uma unidade, ainda que mínima, ao grupo. Por isso, não parece exagero pontuar o fenômeno totalitário como possível apenas a partir da emergência das massas, ou seja, como possível somente a partir do século XX, como, de fato, a própria História mostra.

Evidentemente, se esses condicionantes para o totalitarismo podem ser evidenciados, impossível, também como observado, não aproximar o fenômeno totalitário dos regimes liberais. Afinal, paradoxalmente, é justamente da defesa das liberdades - civis, políticas e econômicas - que os vínculos de unidade para um mundo comum se esfacelam diante de um poder sem rosto.

Um poder sem rosto, aliás, claramente diferente daquele exercido pela figura do rei ou do líder totalitário, mas ainda assim fonte de controle que, principalmente diante das liberdades econômicas, paira acima do Estado, flertando com a dispensa da competição na arena política, abafando, portanto, os conflitos que a pluralidade do tecido social propõe.

É um ponto, sem dúvida, de aproximação das democracias com o fenômeno totalitário. Mas, ainda assim, preso aos indeterminismos históricos, ou seja, ligado ao movimento, ainda que lento, do próprio grupo. Por isso, conclui-se que não é possível, respondendo ao problema proposto e à questão que dá título a esse estudo, pensar o totalitarismo dentro das democracias. Afinal, as essências que formam um ou outro modelo são distintas, em que pesem os pontos de aproximação entre ambos. Contudo, pela própria indeterminação histórica, não é 
uma discussão para ser deixada de lado. Ao contrário. Pois os limites que separam as liberdades do controle são, como observado neste estudo, tênues.

\title{
DEMOCRACY, CONFLICT AND SOCIAL CONTROL: IS POSSIBLE THE TOTALITARIAN PHENOMENON WITHIN THE SAME SOCIETY?
}

\begin{abstract}
Noting the conflict as an important element both in the formation of social bonds, and in the movement of society, this study aims to analyze, from a multidisciplinary approach, the tensions contained in the relationship between group and individual. These tensions come in this text exemplified by those resulting from relationships that threaten both the unity of the social fabric as the freedom of the individual. In other words, this study faces the issue as a problem, apparently paradoxical, that gives title: the totalitarian phenomenon is possible in a democracy? To this end, this text is divided into three parts. At first, looking up, in the light of Freudian thought, recover the theological discussion on human autonomy, the moment that the power of the Church approached political power. In the first half, there was the French Revolution as the time to reverse this thinking, dominant throughout the Middle Ages. In the second part, totalitarianism is observed as the complete suppression of human autonomy, muffling conflicts and braking the movement of society itself. Finally, in the third part, they are subject to the restrictions typical of totalitarianism to democracy. For this research we used the hypothetical-deductive method. Since the technique used was the bibliographical research.
\end{abstract}

Keywords: Democracy; Totalitarianism; Conflict; Social control; State.

\section{REFERÊNCIAS BIBLIOGRÁFICAS}

ARENDT, Hannah. Totalitarismo. Revista Inquietude, v. 2, n. 2, p. 228-237, 2011. Tradução de Adriano Correia. Disponível em: http://www.xanta.milharal.org/ojs/inquietude/index.php/revista/article/view/116. Acesso em 18.02.2015.

Origens do Totalitarismo: antissemitismo, imperialismo, totalitarismo. Tradução de Roberto Raposo. São Paulo: Companhia das Letras, 2012.

BARTEL, Renato Maciel. Ética Contemporânea. Palhoça: Unisul, 2011.

BEDIN, Gilmar Antonio. A Idade Média e o Nascimento do Estado Moderno: Aspectos históricos e teóricos. Ijuí: Editora Unijuí, 2008.

BIELEFELDT, Heiner. Filosofia dos Direitos Humanos: fundamentos para um ethos de liberdade. Tradução de Dankwart Bernsmüller. São Leopoldo: Unisinos, 2000.

BOBBIO, Norberto. O futuro da democracia. Tradução de Marco Aurélio Nogueira. São Paulo: Paz e Terra, 2000.

A Era dos Direitos. Tradução de Carlos Nelson Coutinho. 13 reimp. Rio de Janeiro: Elsevier, 2004. 
CASTANHEIRA NEVES, António. O direito hoje e com que sentido. Lisboa: Piaget, 2002.

CHASIN, José. Sobre o conceito de totalitarismo. Temas de Ciências Humanas, v. 1, p. 121-134, 1977. Disponível em: http:/ / www.verinotio.org/conteudo/0.86711455403558.pdf. Acesso em 19.02.2015.

CORREIA, Adriano. Comentário. In: ARENDT, Hannah. Totalitarismo. Revista Inquietude, v. 2, n. 2, p. 228-237, 2011. Tradução de Adriano Correia Disponível em: http://www.xanta.milharal.org/ojs/inquietude/index.php/revista/article/view/116. Acesso em 18.02.2015.

COTTA, Sergio. Perchè il diritto. 2. ed. Brescia: La Scuola, 1983.

DACANAL, José Hildebrando. Para ler o Ocidente: Hélade, Israel, Roma. Porto Alegre: BesouroBox, 2013.

DAHRENDORF, Ralf. Homo sociologicus: ensaio sobre a história, o significado e a crítica da categoria social. Tradução de Manfredo Berger. Rio de Janeiro: Tempo Brasileiro, 1991.

O conflito social moderno. Um ensaio sobre a política da liberdade. Tradução Renato Aguiar e Marco Antonio Esteves da Rocha. São Paulo: Jorge Zahar Editor, 1992.

DESCARTES, René. Discurso do Método. Tradução de Paulo Neves. Porto Alegre: L\&PM Editores, 2013.

ENRIQUEZ, Eugène. Da Horda ao Estado: Psicanálise do vínculo social. Tradução de Teresa Cristina Carreteiro e Jacyara Nasciutti. Rio de Janeiro: Jorge Zaar Editor, 1990.

FREUD, Sigmund. Totem e tabu: algumas correspondências entre a vida psíquica dos selvagens e dos neuróticos. Tradução de Renato Zwick. Porto Alegre: L\&PM, 2013.

FROMM, Erich. Posfácio. In: ORWELL, George. 1984. Tradução de Alexandre Hubner e Heloisa Jahn. São Paulo: Companhia das Letras, 2009.

HOBBES, Thomas. O Leviatã. Tradução de Rosina D’Angina. São Paulo: Martin Claret, 2009.

HUXLEY, Aldous. Admirável mundo novo. Tradução de Lino Vallandro. Rio de Janeiro: Biblioteca Azul, 2014.

LACLAU, Ernesto; MOUFFE, Chantal. Hegemonía y estrategia socialista. Hacia uma radicalización de la democracia. Madrid: Siglo XXI, 1987.

LEFORT, Claude. Pensando o político: Ensaios sobre democracia, revolução e liberdade. Tradução de Eliana Souza. Rio de Janeiro: Paz e Terra, 1991.

MARX, Karl. Do Capital: o rendimento e suas fontes. Tradução de Edgar Malagodi. São Paulo: Editora Nova Cultural, 1996.

MENDONÇA, Daniel de. A teoria da hegemonia de Ernesto Laclau e a análise política brasileira. Ciências Sociais Unisinos, v. 43, n. 3, p. 249-258, 2007. Disponível em: http://www.revistas.unisinos.br/index.php/ciencias_sociais/article/view/5674. Acesso em: 28.09.2015.

MILOVIC, Miroslav. Freud, Habermas e a questão da política. In: POMMER, Paulo Denisar Fraga; SCHNEIDER, Paulo Rudi. Filosofia e crítica: Festschrift dos 50 anos do Curso de Filosofia da Unijuí. Ijuí: Editora Unijuí, 2007. 
MIRANDOLA, Giovanni Pico Della. Discurso sobre a dignidade do Homem. 1 ed. Lisboa: Edições 70, 2006.

MONTAIGNE, Michel de. Os Ensaios. Tradução de Rosa Freire D’Aguiar. São Paulo: Penguin/Companhia das Letras, 2010.

MOUFFE, Chantal. Por um modelo agonístico de democracia. Revista de Sociologia e Política, n. 25, p. 11-23, 2005. Disponível em: http://www.redalyc.org/pdf/238/23802503.pdf. Acesso em: 23.02.2015.

MORAIS, Jose Luis Bolzan; SPENGLER, Fabiana Marion. Mediação e Arbitragem: alternativas à jurisdição! 3 ed. Porto Alegre: Livraria do Advogado Editora, 2012.

ORWELL, George. 1984. Tradução de Alexandre Hubner e Heloisa Jahn. São Paulo: Companhia das Letras, 2009.

PACHECO, Leandro Kingeski; NESI, Maria Juliani. Filosofia. Palhoça: Unisul, 2007.

PINKER. Steven. Os anjos bons da nossa natureza: Por que a violência diminuiu. Tradução de Bernardo Joffily e Laura Teixeira Motta. São Paulo: Companhia das Letras, 2013.

RESTA, Eligio. Il diritto Fraterno. Roma-Bari: Laterza, 2005.

ROTTERDAM, Erasmo de. Elogio da loucura. Tradução de Paulo Neves. Porto Alegre: L\&PM Editores, 2003.

ROUSSEAU, Jean-Jacques. Discurso sobre a origem e os fundamentos da desigualdade entre os homens. Tradução de Paulo Neves. Porto Alegre: L\&PM, 2009.

SAKAMOTO, Bernardo Alfredo Mayta. Platão como origem do totalitarismo. Revista Pesquisa em Foco: Educação e Filosofia, v. 5, n. 5, 2012. Disponível em: http://www.educacaoefilosofia.uema.br/imagens/5.5.pdf. Acesso em 09.02.2015.

SIMMEL, Georg. Sociologia. Organização de Evaristo de Moraes Filho. Tradução de Carlos Alberto Pavanelli, et al. São Paulo: Ática, 1983.

Soziologie. 5. ed. Berlim: Duncker \& Humblot, 1968.

Sull'intimità. Roma: Armando Editore, 1996.

STEIN, Ernildo. Pensar é pensar a diferença: filosofia e conhecimento empírico. Ijuí: Unijuí, 2002.

Exercícios de fenomenologia. Ijuí: Unijuí, 2004.

TODOROV, Tzvetan. Os inimigos íntimos da democracia. Tradução de Joana Angélica d'Avila Melo. São Paulo: Companhia das Letras, 2012.

TROPER, Michel. Cos'è la filosofia del diritto. Milano: Giuffrè, 2003.

VILLEY, Michel. Filosofia do direito: definições e fins do direito; os meios do direito. Tradução Márcia Valéria Martinez de Aguiar. São Paulo: Martins Fontes, 2003.

VOLTAIRE. Cartas filosóficas. Tradução de Márcia Valéria Martinez Aguiar. São Paulo: Martins Fontes, 2007. 
WEBER, Max. A ética protestante e o espírito do capitalismo. Tradução de Irene Szmerecsányi e Tamás Szmerecsányi. São Paulo: Pioneira/UnB, 1981.

ZAMYATIN, Yevgeny. We. Canadá: Stellar, 2014.

Trabalho enviado em 30 de junho de 2015.

Aceito em 07 de outubro de 2015. 